\title{
Equality of resources, risk, and the ideal market
}

\author{
LARS LINDBLOM \\ Umeå University
}

\begin{abstract}
Ronald Dworkin's theory of equality of resources makes extensive use of markets. I show that all these markets rely on one specific neoclassical conception of the ideal market in full equilibrium, as analyzed by Debreu. This market must be understood as operating under circumstances of certainty, and this is incompatible with several components of Dworkin's account. In particular, it does not allow one to hold people responsible for their option luck, and it implies a high social safety net rather than insurance schemes for addressing brute luck. I conclude by outlining an interpretation of equality of resources that takes the ideal market seriously.
\end{abstract}

Keywords: The market, risk, Dworkin, distributive justice, hypothetical insurance, equality of resources, luck egalitarianism

JEL Classification: A12, B21, D41, D80, D49

When Ronald Dworkin introduced his theory of equality of resources back in 1981, his first claim was that "an equal division of resources presupposes an economic market of some form, mainly as an analytical device but also, to a certain extent, as an actual political institution" (Dworkin 2000, 66, my emphasis). ${ }^{1}$ He then went on to distinguish his use of the market from the two standard ways in which the market has been justified in the debate on economic justice: as an engine of efficiency or as a guarantor of liberty. Dworkin took a different approach: "[T]he idea of an economic market, as a device for setting prices for a vast variety of goods and services, must be at the center of any attractive theoretical development of equality of resources"

\footnotetext{
${ }^{1}$ Dworkin's classic 1981 papers were reprinted as part of his 2000 book, Sovereign virtue, which elaborated his account into a full-fledged theory. I shall follow convention by referring to this book throughout.
}

AuTHOR's NoTE: I wish to thank Sara Belfrage, Kalle Grill, Sven Ove Hansson, Niklas Möller, and Philippe van Parijs for penetrating and helpful comments. 
(Dworkin 2000, 66). Over the following thirty years Dworkin continued to refine his theory, but the market remained a fundamental aspect of his thought on equality. In Justice for hedgehogs, published in 2011, he stated that "[a] free market is not equality's enemy, as is often supposed, but indispensable to genuine equality" (Dworkin 2011, 357). For Dworkin, then, it is necessary to make use of the notion of the market in order to explicate the ideal of equality. The subject of this paper is Dworkin's idea that the market is essential to the normative ideal of equality.

What I shall do is to investigate what the assumptions that Dworkin makes about the market imply for other parts of his theory of equality. I will argue, in section 2, that the market at the core of equality of resources is a neo-classical market in full equilibrium, as analysed by Gérard Debreu. Moreover, I will show that this market must be understood as operating under circumstances of certainty. In section 3, I will begin to spell out the implications of this interpretation of the market for Dworkin's theory of equality. Starting from Dworkin's notion that a just distribution of resources mimics the distribution produced by an ideal market, I will show that the idea of option luck, the normative axiom of individual responsibility for choices under risk usually considered a corner stone of Dworkin's theory, is incompatible with the goal of mimicking such a market. There are no choices under risk when there is complete certainty. The last sections of this article develop the implications of the argument that the goal of justice should be to mimic an ideal market under certainty. In section 4, I argue that this implies a rather high social safety net. Section 5 discusses Dworkin's theoretical solution to the question of how much to redistribute to persons who have been unlucky in the natural lottery. I argue that the thought experiment of insurance purchases behind the veil of ignorance becomes problematic, since there can be no insurance in a market under certainty.

What emerges from this analysis of Dworkin's theory is a new reading of the idea of equality of resources. This interpretation, which may be called the certainty interpretation of equality of resources, is more faithful to the basic motivations of the theory than Dworkin's own version, and retains its most attractive features while alleviating the arguably callous aspects that have been criticized by, for instance, Elizabeth Anderson (1999). 
The aim of this paper is constructive rather than critical. I accept the assumptions that Dworkin makes and do not present any changes to his idea of equality of resources other than those that follow from taking the ideal market seriously. In order to show that these implications follow, I will have to engage in some exegetical work. This paper, then, follows a different strategy from well-known critical contributions by Joseph Heath (2004), John Bennett (1985), and Colin McLeod (1998), which all try to poke holes in Dworkin's ideal market foundations. I do not dispute that there may be problems that have yet to be solved within ideal market accounts. Moreover, I do not in any way dispute that there has been tremendous progress made in economics since Debreu wrote in the late fifties (see Camerer 2003; Bowles 2004). My goal is to investigate the account of the market that Dworkin has placed at the core of equality of resources. My focus is the question of what the ideal market actually commits us to if we accept the Dworkinian framework, and I will try to show that the implications of equality of resources are both different and in many ways more attractive than they appear at first sight.

\section{DWORKIN'S MARKETS}

Dworkin's idea of equality of resources has many attractive features. It provides an interpretation and synthesis of two compelling principles: that it is equally important that each life goes well, and that persons are responsible for their ambitions. It presents a plausible conception of equality in the sense of equal treatment, while, as G. A. Cohen famously pointed out, incorporating the enemy's most dangerous weapon by making a place for responsibility within egalitarian theory (Cohen 1989, 933). By modelling justice on the workings of the ideal market under fair starting conditions, it also connects equality with efficiency. When Dworkin's market has done its work the end result is a distribution of resources that is just, that follows from the operation of egalitarian principles, and an economy in socially optimal equilibrium. What is there not to like?

In this section, I will outline the core of Dworkin's theory and try to show how the different markets it uses relate and then proceed to argue that the central market is the neo-classical market as systematised in the groundbreaking works of Gérard Debreu (1959), and of Kenneth Arrow and Frank Hahn (1971). This is the kind of market that is modelled in what Dworkin calls the 'pre-auction', and which I argue 
should be understood as taking place under conditions that imply that the parties face choices under certainty and not risk. I shall try to show that this is a view to which Dworkin commits himself, and demonstrate how his emphasis in later writings on the importance of the ex ante perspective, and hence choice under risk, is inconsistent with some core ideals of equality of resources.

The central device that Dworkin uses to explain equality of resources is a specific thought experiment, which starts in the aftermath of a shipwreck. The thought experiment is first developed in the 1981 articles which become chapters 2 and 3 of Sovereign virtue (Dworkin 2000; see also Dworkin 2002; 2004; 2006; 2011). The survivors come ashore on a deserted island and find it, luckily, full of resources. They all agree that no one has a prior claim to any of these resources and decide to hold an auction in order to distribute them fairly to each. An auctioneer is appointed to be responsible for finding the fairest way to price the resources on the island. This job is done in two stages. At the first stage, which is called the pre-auction, the auctioneer is assumed to have perfect foresight and is thus able to predict perfectly the resulting distribution of resources on an ideal market based on the preferences of the immigrants (Dworkin 2000, 155-158). This pre-auction is the fundamental market of Dworkin's theory. It provides the standard against which all other markets are to be evaluated and corrected. I will refer to this market as the ideal market or the pre-auction depending on context.

At the second stage, we come upon slightly more realistic circumstances. The auctioneer creates property rights, with the aim of mimicking under more realistic circumstances the distribution of resources produced by the ideal market of the pre-auction. This means that the outcome of the ideal market is the criterion of just distribution in equality of resources. To achieve her goal the auctioneer must take into account issues, such as externalities, coordination failures, and transaction costs that impede the working of less than ideal markets. This is why the auctioneer "imagines a purer, pre-auction auction in which the participants have perfect knowledge and predictive power, and in which there are no organizational costs" (Dworkin 2000, 158).

The auctioneer uses two principles to come up with the correct bundles to auction off. The principle of abstraction, which insists that

an ideal distribution is possible only when people are legally free to act as they wish except so far as constraints on their freedom are 
necessary to protect security of person or property, or to correct certain imperfections in markets (Dworkin 2000, 148).

It is meant to establish "a strong presumption in favor of freedom of choice" (Dworkin 2000, 148). And the principle of correction, which says that "[c]onstraints on freedom of choice are required and justified [...] if they improve the degree to which equality of resources secures its goal, which is to achieve a genuinely equal distribution measured by true opportunity costs" (Dworkin 2000, 157). These true opportunity costs are identified by the ideal market-the value of what each person has is its value to others. This principle corrects the imperfections of real world markets alluded to in the principle of abstraction by putting restrictions on how resources may be used. ${ }^{2}$ We identify these imperfections by comparing the ideal market (the pre-auction) to more realistic markets. Note that this means that how this ideal market is defined becomes paramount for understanding the implications of Dworkin's theory.

The ideal market is thus fundamental to equality of resources. Dworkin aims to show that the market is indispensable to the theory of justice, and this is the account of the market he places at the centre of his theory of justice. All other markets of the theory are to be corrected if they result in outcomes that diverge from the outcomes generated by the ideal market. Moreover, as we have seen, Dworkin starts out from two motivating principles, one of which is that each person is responsible for his or her ambitions. Now, if the outcomes of a market are the result of externalities or uncertainty, they would not be fully ambition-sensitive, but rather endowment-sensitive, in the sense that they result from the person's situation rather than from his or her ambitions. $^{3}$ This is a further reason for why the ideal market is fundamental to equality of resources.

\footnotetext{
${ }^{2}$ The example that Dworkin uses to explain how the principle of correction works involves zoning regulations concerning the architectural style in which houses can be built in a given town or area $(2000,156)$, but it seems that the implications are rather wide since the auctioneer is supposed to solve all kinds of coordination problems. For example, the principle of correction would seem to mandate taking some goods out of the market altogether, such as those services provided by the military, the judiciary, and the police.

${ }^{3}$ The prices on the ideal market will also be decided by other things than the individual's ambitions, namely other people's ambitions. This might make price levels seem like a kind of externality. However, Dworkin argues that we should not think of
} 
Returning to the shipwreck thought experiment, each so-called immigrant survivor gets an equal amount of clamshells to use as markers in the auction. The immigrants can then bid for the resources they individually prefer, with their whole future lives in mind. The immigrants use the 'envy test' to check that equality is preserved. This notion was developed by economists searching for an alternative to the standard Pareto criterion for use in welfare economics (see Foley 1967; Varian 1974) and says that a justified division is achieved when no one prefers anybody else's bundle of goods to her own. The test is satisfied by the clamshell procedure because if a person envies (i.e., prefers) what someone else has he or she is free to bid for it. When the market has cleared, no one will want to exchange their bundle for anyone else's. In this way every person bears the true opportunity cost of his or her choice of lifestyle, while equality is preserved. Thus, we get a theory that incorporates equality, efficiency, and the value of people taking responsibility for their ends. The resulting allocation satisfies the envy test and is consistent with the optimality thesis of general equilibrium analysis.

The ideal market of the pre-auction, then, is crucial to Dworkin's undertaking. How does it work? We are told to think of the ideal market in the manner outlined by Debreu:

I mean to describe a Walrasian auction in which all productive resources are sold. I do not assume that the immigrants enter into complete forward contingent claims contracts, but only that markets will remain open and will clear in a Walrasian fashion once the auction of productive resources is completed. I make all the assumptions about production and preferences made in G. Debreu, Theory of Value (New Haven: Yale University Press, 1959). In fact the auction I describe here will become more complex in virtue of a tax scheme discussed later (Dworkin 2000, 478, fn2).

Before turning to the assumptions of Debreu's model, let me just point out that the tax scheme mentioned above is based upon the hypothetical insurance markets that will be discussed in later sections. Debreu analyzes a market where resources are defined by their physical attributes, their location, and the time of delivery. This is not quite the everyday concept of resources, but it is close enough for the purposes of

them in terms on luck. Prices indicate true opportunity costs and should be thought of as information (see Dworkin 2000, 68-69). 
equality of resources. Agents, either in their role as producers or as consumers, are rational in the sense that they conform to what comes down to two conditions: complete preordering (the relation of non-strict preference holds over all prospects) and continuity (there is a continuous relationship between physical characteristics and desirability) (Harsanyi 1977). Markets are conceived of as taking place at a point in time where all goods, future and present, are sold (the market clears). As the definition of resources includes the time of delivery, there is no use for any further markets. All possible transactions will have been made. From his assumptions, Debreu proves that, so specified, the market will reach an optimal equilibrium.

This market has several features that would seem attractive from an ethical perspective. It satisfies the Pareto principle and the envy test. ${ }^{4}$ Moreover, since there are full property rights for all goods, there are no externalities. The assumptions also make strategic interaction impossible. And, of course, it fits into Dworkin's more general theory of political morality.

There are no probabilities in this model; agents do not face decisions under risk. Instead, the ideal market should be understood as taking place under circumstances of certainty. In fact, the reason that Arrow and Hahn-in that other classic statement of neoclassical general equilibrium analysis General competitive analysis (1971)-re-introduce the Walrasian auctioneer is to make this point about full information. This neo-classical auctioneer will be recognized from Dworkin's island. On the subject of risk, Debreu says, in the introduction to Theory of value, that he assumes that it is not necessary to point out the limitations of the model:

One may stress here the certainty assumption made, at the level of interpretations, throughout the analysis of Chapters 2 to 6, according to which every producer knows his future production possibilities and every consumer knows his future consumption possibilities (and his future resources if resources are privately owned-otherwise only the future total resources need be known). This strong assumption is weakened, albeit insufficiently, in the last chapter (Debreu 1959, xi).

\footnotetext{
${ }^{4}$ Outcomes that satisfy the envy test must also satisfy the Pareto principle. The reason is that if there is no allocation of goods that anyone would prefer, it is also the case that there is no way to make anyone better off without making anyone else worse off.
} 
This quotation raises an interpretative question about Dworkin. Is he following the Debreu of chapters 2 through 6 , in which the analysis proceeds under the assumption of choice under certainty, or is he working out his thought experiment on the basis of the slightly more realistic chapter 7 , where risk is introduced? I suggest that we should interpret Dworkin according to the first alternative. The textual basis for this interpretation is that Dworkin points out that he does not assume that there are contingent claims contracts, and chapter 7 of Debreu's book deals with such contracts. There are also theoretical reasons. The importance of leaving contingent contracts out of the core of equality of resources can be brought out by considering how Arrow and Hahn present their way of incorporating risk into general equilibrium theory: "Each commodity now must be interpreted as a contingent claim [...] a promise to supply one unit of commodity $i$ if state of the world $s$ occurs and nothing otherwise" (Arrow and Hahn 1971, 124). Debreu puts the same point in the following way:

A contract for the transfer of a commodity now specifies, in addition to its physical properties, its location and its date, an event on the occurrence of which the transfer is conditional. This new definition of a commodity allows one to obtain a theory of uncertainty free from any probability concept and formally identical with the theory of certainty developed in the preceding chapters (Debreu 1959, 98).

This is an elegant move that brings risk into the analysis by redefining goods. Debreu's initial definition of resources seemed suitable for a conception of equality that takes the perspective of equality as measured over whole lives. But now we have a new definition of commodities, where what is traded are contingent claims. On this new interpretation of the theory, goods are no longer concrete resources, but rather lotteries. The metric of justice becomes inherently risky. It seems clear that Dworkin should prefer the certainty interpretation. The reason for this is that if Dworkin accepted the move from concrete resources to this kind of commodity, the equalisandum of equality of resources would change from resources, understood in the commonsensical way, to lotteries. This would be a whole different theory.

There is, however, some reason to suspect that Dworkin would not agree with this. In a more recent article he says: "True equal concern requires ex ante, not ex post, equality" (Dworkin 2002, 124). This implies that people should be held responsible for how they approach risky 
choices as a fundamental feature of equality of resources, and it suggests that Dworkin would prefer to include risk in the model of the ideal market. In other words, this would amount to a risk interpretation of the ideal market.

To see why such an inclusion of risk is problematic for strictly Dworkinian reasons, we must ask why we ought to take resources, and not welfare for instance, as the equalisandum of justice. Dworkin argues that the notion of fair shares of resources is needed to make sense of the ideal of equality, which is shown by the failures that he finds in welfare conceptions of egalitarianism (Dworkin 2000, chapter 1). For instance, we do not want to compensate people for having frustrated preferences for unfairness. Furthermore, with resources as our metric we can hold people responsible for their choices in an appropriate way, for instance in expensive taste cases. A third reason is brought out in this quotation:

People make their choices, about what sort of a life to lead, against a background of assumptions about the rough type and quantity of resources they will have available with which to lead different sorts of lives. They take that background into account in deciding how much of what kind of experience or personal relationship or achievement of one sort must be sacrificed for experiences or relationships or achievements of another (Dworkin 2000, 28-29).

This implies that having at least a rough idea of what resources will be under one's command is a precondition for the responsible agency demanded by his theory of justice. Dworkin argues that welfarist theories cannot take this point into account. The distribution of resources in society will be a function of the distribution of preferences in society. If preferences change, then so must the distribution. People need some sense of security with regards to what resources will be available to them in order to make decisions on how to live their lives and consequently what choices to make and what preferences to form. But if this is true then the risk interpretation of the ideal market turns out to distribute the wrong things. If the auctioneer is going around distributing lottery tickets then it will be as difficult under equality of resources as under equality of welfare to plan one's life. If such uncertainty counts against equality of welfare it must also count against the ex ante approach. On the basis of Dworkin's own argument, then, we should prefer the ex post approach, since this gives us a more 
appropriate equalisandum. In other words, for Dworkinian reasons we should prefer the certainty interpretation of the ideal market.

To be clear, the question we are investigating now is what a theory of justice should distribute, not how it ought to distribute it. ${ }^{5}$ But including risk in our description of the market, through the definition of resources, means that there can be some disturbing inequalities in resources, independently of any choice. Such inequalities will not depend on differences in people's ambitions, but on the luck of the draw. Including risk in the equalisandum severs the connection between responsibility and resources.

These two different approaches to risk and certainty suggest the following distinction between theories of equality: equality of resources is concerned with the distribution of concrete things (such as oranges). A theory of equality of commodities would concern the distribution of contingent claims (such as the probability of having an orange on Tuesday in Brussels). It is fairly evident that these theories will evaluate distributions rather differently. Equality of commodities has some unappealing consequences. In terms of a decision tree, equality of commodities is in principle consistent with all of your actual resources being situated on branches that are never instantiated. Or if we put this in terms of an Edgeworth box, achieving an envy-free allocation of commodities from equal starting points is consistent with the actual distribution of, say, apples and oranges being at the origin of one of the players. ${ }^{6}$ Or, finally, in everyday terms, perfect equality of commodities is consistent with perfect inequality of resources. Equality of commodities is both inegalitarian, since these differences in allocation do not depend on choice but on what we have chosen as the equalisandum of the theory of justice, and in violation of the demand that people should have a secure sense of what resources they will have available when planning their lives. It would undermine Dworkin's theory of equality to incorporate risk into the ideal of the market in this way.

\footnotetext{
${ }^{5}$ And note that what we are discussing here is the fundamental criterion of justice and not the issue of how to implement justice. It would be quite unrealistic to think that we could avoid uncertainty when we are trying to achieve justice in the world, but this does not mean that we should valorise uncertainty at the level of fundamental principle. I return to the issue of implementation in the later part of section III.

${ }^{6}$ For a quick explanation of Edgeworth boxes, see Bowles 2004, 209-210; and for decision trees, see Peterson 2009, 17-19.
} 
To sum up, the way Dworkin introduces and explains the ideal market suggests that it ought to be understood as taking place under certainty. Furthermore, if risk is included in the model of the market this has two unfortunate consequences for equality of resources. First of all, it changes the equalisandum of the theory from actual resources to Debreu's commodities. Second, if one takes this step to commodities, one allows inequalities in terms of resources that are not the result of people's choices or ambitions, since, as we have seen, this kind of commodity is in fact a lottery ticket. A move to lottery tickets would mean that Dworkin must give up on ambition-sensitivity. For these reasons, I submit that if Dworkin wants to use the ideal market as characterized in Debreu's analysis, then he is, or ought to be, committed to model the market on choices under certainty, and not under risk. ${ }^{7}$ In the following sections, I will draw out the implications of this certainty interpretation of Dworkin's theory.

\section{OPTION LUCK IN THE IDEAL MARKET}

We turn now from the question of what should be distributed, to how these things should be distributed. One of the most path-breaking aspects of equality of resources is that it introduced a way for egalitarian theories to take risk into account, through the concept of option luck. This is the part of Dworkin's theory where risk is actually introduced as a consideration. To see how, let us return to the island thought experiment.

After the auction, the immigrants get on with their lives, and further trade ensues. Here we come upon real-or at least realistic-markets. This is then the third type of market in equality of resources, which is, of course, constrained by the two previous markets. As time goes on, some people will have worked more than others, some will have fallen sick, some will have been lucky in business, or unlucky, and some will have had accidents. As a result, the envy test will no longer be satisfied. Since the goal of equality of resources is that the distribution of resources is ambition-sensitive, but not endowment-sensitive, the

\footnotetext{
${ }^{7}$ Another conclusion one could draw is that neoclassical economics is not the best way to model what Dworkin wants to capture; perhaps an account of the market that takes transaction costs into consideration would be more suitable. It would certainly be more realistic, but it would almost as certainly be less compelling. Why would justice demand that we take the lack of knowledge or the existence of strategic action into consideration at the level of principle? These phenomena make the world, if anything, worse, rather than better.
} 
inequalities resulting from such contingencies must be rectified before the market can achieve a fully justified envy-free distribution of resources. This is why the hypothetical insurance scheme is needed. In fact there are several such schemes; there are schemes for general health, unemployment, and handicap insurances as well as a scheme that deals with the taxation of inheritance. I will not discuss the inheritance tax insurance scheme, as it seems to me that the inequalities that result from differences in bequest are best understood as externalities, and as such they fall directly under the domain of the principle of correction. Letting inherited wealth affect the price mechanism means that the prices will be distorted in comparison with the baseline, where each person has equivalent purchasing power, in the form of an equal amount of clamshells. If justice demands that we mimic the distribution of an ideal market, and that this distribution should be endowment-insensitive, we cannot let these kinds of endowments play a role. I will deal with the special issues that handicap insurance raises in a later section, and health and unemployment insurance in this section.

It is here that Dworkin invokes the famous distinction between brute luck and option luck. Option luck has to do with how deliberate gambles turn out: for instance if a person decides to play the stock market and loses his or her money-or, for that matter, gets very rich. Brute luck concerns unforeseeable events, such as being hit by a meteorite, or in the case of brute good luck, stumbling upon a lost treasure. The idea is that the effects of brute luck ought to be rectified, but that it is fair that people are held responsible for their choices, and hence for their option luck. Insurance provides a bridge between brute and option luck. If it is available, then, Dworkin says, brute luck is converted into option luck, since the choice of whether to insure or not is a deliberate gamble in the right way. ${ }^{8}$ Thus, the envy test can still be satisfied ex ante. Someone who prefers to play it safe can buy insurance, while risk-takers can choose to go without a safety net. After a person has received his or her equal endowment, he or she is fully responsible for the outcomes that ensue. Ambition-sensitivity and responsibility for option luck seem to overlap.

The immigrants, in possession of equal shares of resources, are asked to consider a situation where the risk distribution of something

\footnotetext{
${ }^{8}$ But see Michael Otsuka 2004 for important qualifications.
} 
bad, for instance serious disease, remains as it is, but where they are placed behind a veil of ignorance, so that they do not know if they will be unlucky or not. Next, they are asked what level of insurance they would buy against illness when the veil is lifted. In line with this choice, their resources are then taxed and redistributed to those who qualify for payments. This scheme has several virtues, Dworkin claims, such as that it gives reasonably precise answers to the question of how much should be redistributed and that it permits rational trade-offs between health and other goals in life. The immigrants will, if rational, not spend all their resources on insurance, because they will have to be concerned with having a decent life after making their insurance payments. The scheme also takes into account the costs of running the system, in that the model incorporates the demand for profits under which insurance firms would operate. The implication of the last two points is that the envy test can only be approximately satisfied, because the envy at the start of trading will not be eradicated by the transfers of the insurance scheme, but it will, Dworkin argues, come close enough for the purposes of equality of resources. ${ }^{9}$

There is much to admire about this attempt to handle risk within an egalitarian theory. However, I shall argue that the notion of option luck cannot play a fundamental role in equality of resources since it is incompatible with the characteristics of an ideal market. If justice demands that we mimic the ideal market, then holding people responsible for their choices in the manner indicated by the argument from option luck lacks a fundamental motivation in the theory of

\footnotetext{
${ }^{9}$ It is not always clear if the redistribution effected by the insurance market should be understood as taking place before the pre-auction, which would then ensure that each immigrant had equal resources at the start of the auction, or if we are to think of insurance as patching up the market after the fact. As can be seen from the way I formulate this query, I prefer the first alternative. I have the feeling that Dworkin has the second way of thinking in mind; the recurrent use of the term 'compensation' would indicate this. In recent work, the insurance market seems to have become even more central to Dworkin's position, whereas other markets have dropped from view. In Dworkin's "Sovereign virtue revisited" (2002) and Is democracy possible here? (2006), one gets the impression that the only demand that the theory presents is that there should be a social insurance system that mimics the ideal insurance market, and that one need not ensure that people start out with roughly equal shares. This does not seem to me to be a fully egalitarian position and perhaps a name like 'the compensation view of resources', rather than equality of resources, would be more appropriate. I shall therefore continue to interpret Dworkin as requiring a role for equality in all markets, not just the insurance market. At any rate, this seems to me a much more attractive view.
} 
equality of resources. Ambition-sensitivity and option luck do not overlap. Consider how Dworkin introduces the concept of option luck:

Option luck is a matter of how deliberate and calculated gambles turn out-whether someone gains or loses through accepting an isolated risk he or she should have anticipated and might have declined. Brute luck is a matter of how risks fall out that are not in that sense deliberate gambles (Dworkin 2000, 73).

The idea of option luck, then, is characterized by analogy with gambling. There are several possible actions that you choose between based on the odds and the values you attach to the different states of the world that might result. Gambling is decision-making under risk, but, as we have seen, in the ideal market people face decisions under certainty. There can be no such deliberate gambles where there is no risk. And if there are no such gambles, then there is no room for the application of the concept of option luck. Obviously, there are optionsone can choose between apples and oranges, say-but these have nothing to do with luck. If the ideal of the market is to be retained, then the idea of option luck cannot be fundamental to the theory of equality of resources. Full ambition-sensitivity can only be achieved by dropping option luck. The point of Dworkin's theory is to hold people accountable for their ambitions, not to hold them responsible for having to choose under conditions of risk. He wants to capture choices concerning what we want to do with our lives: if we prefer to work hard or enjoy our leisure, or if we want to, in Kenneth Arrow's well-known terms, drink pre-phylloxera claret and eat plovers' eggs, rather than fulfil more mundane tastes (Arrow 1973, 254). Such ambition sensitive distinctions remain valid, even if we find that the idea of option luck should not play a role in equality of resources. If the ideal market is indispensable, then we cannot dispense with it here.

This is where the distinction between the pre-auction, the auction and actual markets makes itself useful. The pre-auction is the core market of equality of resources, and it is here that we should not let risk play any role. There are no gambles in the pre-auction for later markets to mimic. On the other hand, it is obvious that we encounter risk and uncertainty in our daily lives, and that at least sometimes we feel that people should be held accountable for how they approach risky situations. The auctioneer, using the principle of correction, must try to devise a market that mimics the ideal market as closely as possible. 
Never holding people in real markets responsible for how they approach risk would be an inefficient way of achieving this. Moreover, in real markets there will be, and should be, insurance. The argument that there is no uncertainty in the ideal market does not mean that there will not be risky purchases in actual markets. But from the idea that when designing institutions it is reasonable, for efficiency reasons, to incorporate a concern for responsibility for risky choices, it does not follow that such a responsibility should be thought of as a fundamental aspect of the normative theory. The pre-auction takes place under certainty, but when the auctioneer has developed the set of property rights to auction off in the actual market, as it were, then we can take something resembling the ex ante approach.

To return to the lottery metaphor, in realistic settings there will be lotteries, but their prizes should be such that the outcome mimics the distribution on the ideal market. The pre-auction decides the prize structure. Furthermore, note that saying that risk is not fundamental to equality of resources is not the same as saying that responsibility for one's preferences cannot be fundamental to equality of resources. Responsibility for ambitions is fundamental for equality of resources, but responsibility for risk is not. If one finds oneself facing a decision under risk, one finds oneself with a deficit of that highly valuable resource: knowledge concerning how the world will turn out. ${ }^{10}$

How about brute luck? This concept is also defined in a way that seems to include risk. Does this mean that it must also be dropped from equality of resources? It does not seem so because it is, I believe, better to interpret the term risk in the definition of brute luck as unwelcome outcomes, rather than in the way that term is understood in the theory of decision under risk. The concept of brute luck does not concern the choices you face, but rather the fortune that faces you. Even under certainty there will be outcomes that are tragic; uncertainty and unfortunate outcomes are distinct phenomena. That it is certain that you will become ill does not make it any less of a misfortune. Perhaps brute (mis)fortune would be a better term than brute luck, but the concept can be applied regardless of whether certainty or risk is at issue.

\footnotetext{
${ }^{10}$ Not only does having full information help with preference satisfaction, it also makes strategic interaction impossible and internalizes externalities.
} 
To see the implications of this certainty interpretation of equality of resources and of dropping option luck, it is instructive to turn to the charge of callousness made by Elizabeth Anderson (1999). The core of her criticism can be brought forth by considering three of her best known counterarguments to luck-egalitarian theories like equality of resources. The abandonment of negligent victims points out that it is an implication of equality of resources that ambulances should pass by the uninsured victims of accidents. Since only bad brute luck should be compensated, it follows that the results of bad option luck are of no concern to justice. A related problem is the abandonment of the prudent. This is where a person makes every reasonable choice, but has bad luck repeatedly and ends up unable to pay for insurance. These problems present theoretical difficulties for equality of resources, even if it is hard to think of realistic scenarios where they would appear.

If, however, I am correct in saying that equality of resources is best understood under the certainty interpretation, then these counterarguments are blocked. In both abandonment problems the trouble starts from taking or having to take risks - and then insisting on holding people responsible for their option luck. But the idea of option luck does not make sense as a fundamental aspect of equality of resources, since there is no room for the application of that concept on the ideal market. If we are to mimic the ideal market, then we cannot let option luck influence the distribution of resources. This means that these two charges cannot be made to stick against the certainty interpretation - a further reason to prefer this interpretation of equality of resources.

There is, however, a third aspect of Anderson's charge of callousness that cannot be answered in this way. This is the problem of the lack of a safety net. Even if option luck is dropped from the fundamental level of the theory, there is still no guaranteed minimum outcome. It might still be the case that a person makes choices that lead to destitution, and then it would seem that justice according to equality of resources would demand that this person is left destitute. If we find a theory of equality that allows for some people having absolutely nothing unattractive, then we will feel that little ground has been gained by excluding option luck. In the next section we will turn to the question of a social safety net. 


\section{RATIONALITY AND A SOCIAL SAFETY NET IN THE IDEAL MARKET}

I believe that under the certainty interpretation the notion of mimicking the market gives us an answer to Anderson's safety net argument. To see how the fact that the ideal market operates under certainty does this, we have to look into the different implications of the assumptions of choice under certainty and under risk.

Imagine a situation where Adrian can choose between two alternatives. In A he is guaranteed $€ 5$, and in B he can either end up with $€ 100$ or nothing, with a probability of 0.1 and 0.9 respectively. Assuming a linear relationship between utility and money, and risk neutrality, the expected utility of option A is 5 and for B it is 10. A rational person would then choose $\mathrm{B}$, as this affords the highest level of expected utility. This seems to imply that if we are trying to mimic the market we should see to it that option B is implemented. Most of the time, then, justice would demand that Adrian receives nothing. This, however, is not the choice that Adrian would face in the neo-classical world described in Debreu's model of a market with perfect foresight; there are no probabilities in that world. The theory of rational choice under certainty says that if one knows with certainty what will happen, then one should chose the option with the outcome that one prefers the most. Nine times out of ten (not the best way of putting it, but the charitable reader will understand what I mean) he would stand before these options: $\mathrm{A}=5$ and $\mathrm{B}=0$. In these cases, mimicking the market would mean implementing $\mathrm{A}$ and not $\mathrm{B}$.

A rational individual such as Adrian would not choose B unless A is no longer a live option. This example presents two considerations in favour of a social safety net. First, equality of resources says that a justified distribution is the result of trade from equal starting points in an ideal market; and second, it is clearly a violation of Pareto efficiency to choose to make oneself worse off than the baseline. Any transaction that left the traders worse off than the baseline of equality would not take place and therefore should not be permitted by real world institutions attempting to mimic the operations of the ideal market.

Adrian's decision at the auction would obviously be much more important than the choice we just discussed since he is making a one-off choice that will affect the rest of his life. But his choice will be based on the same principle. He has been given an equal amount of clamshells, and, since he does not face any choice under risk, he is in fact guaranteed the corresponding level of resources in terms of the prices 
set at the auction. Any trade that he makes will have to be an improvement. When the auctioneer is applying the principle of correction she will have to take this baseline as a floor that limits the level of inequality.

An assumption of Dworkin's is that the parties to the auction trade with the goal of making the whole of their lives as valuable for themselves as possible. Under certainty, this seems to require that they will see to it that they have a sufficient level of resources for food, shelter, health care, and so on throughout their lives. "When I am 36 I will not need food" would clearly be irrational if one planned to live to 37 or longer. A rational individual choosing under certainty, and endowed with an equal share of purchasing power, would plan his or her life so as to have a sufficient level of resources at any time during his or her life.

The argument makes some mild assumptions about the content of peoples' preferences: they care about their futures. But these are the same assumptions that are needed to get the 'right' answers in Dworkin's original argument. If a person is prudent enough to buy hypothetical insurance then he or she will choose to get the same level of protection in a choice under certainty. However, note that it is not irrational to not care about the future. It is difficult to think that a person would spend all his or her resources in youth and then spend fifty years in poverty if this choice were made with full information, including information about the effects of poverty. But, of course, rationality in itself does not rule out such preferences. If Dworkin's assumptions about how people care about their own futures are wrong, then equality of resources, even under the certainty interpretation, would not require a high safety net. However, similar assumptions are shared by all theories that give preferences this kind of role when it comes to risk; it is not a problem specific to the certainty interpretation. The aim of this paper is to draw out the implications of Dworkin's theory rather than to develop an external critique. Therefore, the argument will continue under the assumption that Dworkin is right about how people would make these kinds of choices.

Dworkin's principle of correction, then, implies that the auctioneer should set up property rights so that the immigrants never fall below the level of sufficient resources. Furthermore, it would take unwelcome outcomes out of the market if they are of a type that no one would rationally choose. For example, the auctioneer will have to design 
property rights that leave each immigrant with guaranteed health care and sufficient resources if unemployed. If the result of trade on the ideal market is that people would have access to resources of this kind over their whole lives, then this is something that the auctioneer must replicate when designing property rights.

The social minimum will therefore be rather high. ${ }^{11}$ The distribution will be ambition-sensitive; there is room for the trade-off between work and leisure, or between beer and pre-phylloxera wine. The parties will have to take into consideration the true opportunity costs of their choices. The one thing that the distribution cannot vary with is ignorance.

This argument does the same work as the insurance schemes for health care and employment do and therefore these two insurance schemes are not needed in the theory anymore. The attractive features of equality, responsibility, and efficiency are retained in a version of equality of resources that drops the ideas of option luck and these types of insurance. We have yet, however, to discuss the hypothetical insurance market that is devoted to the issue of handicaps.

\section{INSURANCE, HANDICAPS, AND THE IDEAL MARKET}

In the previous two sections, I have made two points. First, that option luck is inconsistent with the idea of mimicking the ideal market, and second, that several of Dworkin's insurance thought experiments are unnecessary under the certainty interpretation of equality of resources. In this section, I will make a related but distinct claim, namely that the notion of insurance itself is incompatible with the ideal market.

The story of the immigrants has up until now assumed equality of personal resources, i.e., equal talents and no handicaps. However, in Dworkin's scheme insurance does more than bring personal responsibility for risk into equality of resources; it also redistributes. It provides a way of fixing inequality of personal resources, such as physical and mental capacities. In order to achieve full equality of resources, some process of justice must equalise the combined value of personal and impersonal resources. Dworkin argues that a hypothetical insurance market could be used to derive answers to the question of what redistribution is required for true equality. Note that this is a

\footnotetext{
${ }^{11}$ The exact amount will, however, vary according to the size of a society's total social product. It will be higher in rich countries and lower in less well off societies.
} 
further use of the ideal market in Dworkin's theory, which means that this insurance market must be compatible with the characteristics of the ideal market. This hypothetical insurance market is designed to redistribute impersonal resources so that we make up for any inequality in personal resources. Even if insurance is superfluous with regards to the problems we discussed above, it could be necessary for dealing with the problem of inequality in personal resources.

However, there is a problem. Insurance and the ideal market do not go very well together. As Ronald Coase pointed out: "when there are no costs of making transactions, it costs nothing to speed them up, so that eternity can be experienced in a split second" (Coase 1988, 15). The importance of this point, for our purposes, becomes more evident when we consider a quotation from Stigler on the previous page in Coase's book: "The world of zero transaction costs turns out to be as strange as the physical world would be without friction. Monopolies would be compensated to act like competitors, and insurance companies would not exist" (Stigler 1972, 12; see also Stigler 1966). There cannot be any insurance if the future is fully known. You will never be able to insure your car if it is certain that you will crash. The idea of insurance lacks any foundation if there is no risk. We cannot consistently use the ideal market to argue for the hypothetical insurance scheme as a fundamental feature of equality of resources. If justice demands that we mimic the ideal market of the pre-auction, then we cannot, at the same time, mimic a market where there is insurance, and hence uncertainty. This thought experiment is inconsistent with how an ideal market works.

We should not confuse the uncertainty that is introduced by the veil of ignorance with the kind of uncertainty needed to get the notion of insurance off the ground. The veil introduces risk concerning your identity in order to define an impartial-fair-standpoint between ourselves and others; insurance concerns individual vulnerability to future contingencies. Just introducing the veil of ignorance does not lead us to a coherent idea of insurance. ${ }^{12}$ To see why, consider two

\footnotetext{
${ }^{12}$ It should probably be noted that it is even controversial whether the veil of ignorance works as Dworkin supposes. John Roemer argues that the parties behind the veil would allocate more resources to those who are most able to use them efficiently in the pursuit of utility, and so the healthy would get all the money (Roemer 1996, chapter 7). Marc Fleurbaey (2002) makes a similar point. Dworkin, however, has replied that this kind of argument relies on an account of the motivation of the parties that is far from self-evidently true. People care not only about the expected aggregate level of utility, but also about their own futures.
} 
different choices behind a veil of ignorance. In the first case you know the following: Peter and Paul will both get $\$ 100$, but you do not know if you are Peter or Paul. In the other case you are either Penny or Paula, but you do not know which. Penny will either get $\$ 100$ or nothing, and Paula will get either $\$ 20$ or $\$ 80$. In both cases, there are veils of ignorance, but only in the second case are there contingencies. Therefore, contingencies and the veil of ignorance are distinct.

Clearly, the auctioneer could design a system of handicap insurance for the auction, but this would not make the idea of insurance any more fundamental to equality of resources than zoning restrictions are. The pre-auction would still be the standard that we should use to evaluate the workings of this insurance market. Dworkin's argument is that an insurance market could, in principle, solve the problem of how to redistribute in order to compensate for brute luck, but it seems to me that it is the market, rather than insurance, that is essential to his solution. More precisely, what is essential is that the auctioneer finds a way of measuring the size of the personal inequality deficit, so that she can redistribute impersonal resources in a way that achieves net equality.

The ideal market is essential for Dworkin's theory, whereas the insurance model is not. The hypothetical insurance scheme is best understood, I believe, as a tool for measuring the equality deficit brought about by the initial inequality of personal resources. It puts a price on personal resources, and redistributes impersonal resources until rough net equality ensues. It sets this price by asking the immigrants how much of their impersonal resources they would be willing to forgo in order to avoid ending up in an unwelcome situation. This understanding of the insurance mechanism-as a tool that helps us set a price on inequalities of personal resources - is still open to us under the certainty interpretation..$^{13}$ But, if Dworkin's hypothetical insurance markets are best understood as tools, then we should ask if there are better tools available. Again we have come to the conclusion that the aspects of equality of resources that have to do with risk are best understood as means to achieve the equal division of goods that would be the outcome of an ideal market.

\footnotetext{
${ }^{13}$ Understood this way, the debate between Roemer and Dworkin is not about whether the mechanism is utilitarian or not, but about the correct value of the inequality deficit.
} 


\section{CONCLUDING REMARKS}

My purpose in this paper has been to show that if we take the ideal market seriously, the implications of equality of resources are different and perhaps more attractive than is usually thought. The argument presented has the following form: according to Dworkin, mimicking the ideal market from equal starting points is fair. In this market, as described by neoclassical economics, trade takes place under full information, which rules out choices under risk. Therefore, there can be no such thing as option luck in the ideal market. Consequently, one cannot and should not hold people responsible for option luck in equality of resources. Moreover, mimicking this market implies that the principle of correction will direct us to set up a social safety net. Given Dworkin's assumptions about the motivations of rational agents, it follows that rational agents choosing under certainty would make sure to have access to enough resources at each point in time to carry out their life plans. This makes several of the hypothetical insurance schemes unnecessary to equality of resources. In relation to inequality in personal resources, I have also argued that the idea of insurance is incompatible with the conditions of certainty that define the ideal market.

This certainty interpretation of equality of resources would not be vulnerable to various well-known criticisms from callousness. In addition, the revised theory is more true to the core tenets of Dworkin's equality of resources than his original formulation-especially the central notion that the market should play a fundamental role in the theory of equality. It is based on a more thorough and consistent understanding of the ideal market, and still makes room for a difference between endowments and ambitions. The market continues to be crucial to the theory of equality of resources, but it no longer allows risk and option luck to play roles in deciding what is just.

\section{REFERENCES}

Anderson, Elizabeth S. 1999. What is the point of equality? Ethics, 109 (2): 287-337.

Arrow, Kenneth. 1973. Some ordinalist-utilitarian notes on Rawls's Theory of justice. Journal of Philosophy, 70 (9): 245-263.

Arrow, Kenneth J., and Frank H. Hahn. 1971. General competitive analysis. San Francisco: Holden-Day Publisher.

Bennett, John. 1985. Ethics and markets. Philosophy and Public Affairs, 14 (2): 195-204. Bowles, Samuel. 2004. Microeconomics: behavior, institutions and evolution. Princeton: Princeton University Press. 
Camerer, Colin. 2003. Behavioral game theory: experiments in strategic interaction. Princeton: Princeton University Press.

Coase, Ronald H. 1988. The firm, the market, and the law. Chicago: The University of Chicago Press.

Cohen, G. A. 1989. On the currency of egalitarian justice. Ethics, 99 (4): 906-944.

Debreu, Gérard. 1959. Theory of value. New Haven: Yale University Press.

Dworkin, Ronald. 2000. Sovereign virtue: the theory and practice of equality. Cambridge (MA): Harvard University Press.

Dworkin, Ronald. 2002. Sovereign virtue revisited. Ethics, 113 (1): 106-43.

Dworkin, Ronald. 2004. Reply to critics. In Dworkin and his critics, ed. Justine Burley. Malden (MA): Blackwell Publishing, 339-395.

Dworkin Ronald. 2006. Is democracy possible here? New Jersey: Princeton University Press.

Dworkin, Ronald. 2011. Justice for hedgehogs. Cambridge (MA): The Belknap Press.

Fleurbaey, Marc. 2002. Equality of resources revisited. Ethics, 113 (1): 82-105.

Foley, Duncan K. 1967. Resource allocation and the public sector. Yale Economic Essays, 7 (1): 45-98

Harsanyi, John. 1977. Rational behavior and bargaining equilibrium in games and social situations. New York: Cambridge University Press.

Heath, Joseph. 2004. Dworkin's auction. Politics, Philosophy and Economics, 3 (3): 313335.

MacLeod, Colin M. 1998. Liberalism, justice, and markets: a critique of liberal equality. New York: Oxford University Press.

Otsuka, Michael. 2004. Equality, ambition, and insurance. Proceedings of the Aristotelian Society (Supplement), 78 (1): 151-166.

Peterson, Martin. 2009. An introduction to decision theory. Cambridge: Cambridge University Press.

Roemer, John E. 1996. Theories of distributive justice. Cambridge: Harvard University Press.

Stigler, George J. 1966. The theory of price, 3rd ed. New York: Macmillan.

Stigler, George J. 1972. The law and economics of public policy: a plea to the scholars. Journal of Legal Studies, 1 (1): 1-12.

Varian, Hal R. 1974. Equity, envy, and efficiency. Journal of Economic Theory, 9 (1): 6391.

Lars Lindblom is a senior lecturer at Umeå University. He works on issues in the intersection between political philosophy and economics. He has written on topics such as invisible hand explanations in Nozick's political philosophy, incomplete contract theory and consent in business ethics, and responsibility-catering prioritarianism and risk management. Contact e-mail: <lars.lindblom@umu.se> 